\title{
Low-Power Class-AB CMOS Voltage Feedback Current Operational Amplifier with Tunable Gain and Bandwidth
}

\author{
Fermin Esparza-Alfaro, Salvatore Pennisi, Senior Member, IEEE, Gaetano Palumbo, Fellow, IEEE \\ and Antonio J. Lopez-Martin, Senior Member, IEEE
}

\begin{abstract}
A CMOS class AB variable gain Voltage Feedback Current Operational Amplifier (VFCOA) is presented. The implementation is based on class $\mathrm{AB}$ second generation current conveyors and exploits an electronically tunable transistorized feedback network. The circuit combines high linearity, low power consumption and variable gain range from 0 to $24 \mathrm{~dB}$ with nearly constant bandwidth, tunable from 1 to $3 \mathrm{MHz}$. A prototype has been fabricated in a $0.5-\mu \mathrm{m}$ technology and occupies a total area of $0.127 \mathrm{~mm}^{2}$. The VFCOA operates using a 3.3-V supply with static power consumption of $280.5 \mu \mathrm{W}$. Measurements for maximum gain configuration show a dynamic range (1\% THD@300kHz) of $87.5 \mathrm{~dB}$ and a THD lower than -40dB for an output current 23 times the bias current.
\end{abstract}

Index Terms - CMOS analog integrated circuits, voltage feedback operational amplifier, current mode, class AB, current amplifier, quasi-floating gate transistor, current mirror, current conveyor, operational amplifiers.

\section{INTRODUCTION}

$\mathrm{T}$ HE most popular analog building block is the Voltage Operational Amplifier (VOA). Because of the wide variety of achievable transfer functions, it is used to implement high complexity circuits such as filters, amplifiers, $\mathrm{A} / \mathrm{D}$ and $\mathrm{D} / \mathrm{A}$ converters, $\mathrm{V}-\mathrm{I} / \mathrm{I}-\mathrm{V}$ converters, etc. [1]-[3]. When designing wideband circuits, the main VOA limitation is its constant gain-bandwidth product. On the other hand, the Current Feedback Voltage Operational Amplifier (CFVOA) has constant bandwidth independent of the gain [4]-[7].

Since some sensors and transducers provide an output signal in current form, it is desirable in these cases to process the signal directly in the current mode (CM) domain. Highperformance implementations of the $\mathrm{CM}$ equivalents of the VOA and CFVOA, (named Current operational amplifier,

Manuscript received; This work has been supported in part by the Spanish Direccion General de Investigacion under grant TEC2010-21563-C0201/MIC.

Fermin Esparza-Alfaro and Antonio J. Lopez-Martin are with the Department of Electrical and Electronic Engineering, Public University of Navarra, 31006 Pamplona, Spain (e-mail: fermin.esparza@unavarra.es; antonio.lopez@unavarra.es).

Salvatore Pennisi and Gaetano Palumbo are with the Dipartimento di Ingegneria Elettrica Elettronica e Informatica (DIEEI), University of Catania, Catania I-95125, Italy (e-mail: spennisi@dieei.unict.it; gpalumbo@diees.unict.it).
COA [8]-[9] and Voltage Feedback Current Operational Amplifier, VFCOA [10]-[12], respectively) are therefore required. Note that being COAs the CM counterpart of VOAs, they are still bounded to the constant gain bandwidth product. Instead, the VFCOA combines the constant bandwidth property with the possibility of using non-linear resistors in the feedback loop without penalty in the overall circuit linearity [13], becoming a very interesting option for designing wideband circuits.

In this paper a novel low-power class AB VFCOA with transistorized feedback network is presented. Section II introduces its basic operation. The proposed implementation is shown in Section III, followed by the experimental results in Section IV. Conclusions are drawn in Section V.

\section{Voltage FeEdBack CurRent OPERATIONAL AMPLIFIER}

\section{A. General considerations}

The VFCOA can be modeled as a single-ended input differential-output current controlled current source, where the input and positive output terminal are low impedance nodes and the negative output terminal is a high impedance node. Fig. 1 shows the VFCOA's symbol and equivalent circuit with the feedback configuration used to achieve accurate current gain. Main properties of this amplifier will be outlined below.

The VFCOA can be represented with the block diagram in Fig. 1b made up of a trans-impedance amplifier and a current follower. The transimpedance amplifier converts the input current into a voltage, $Z_{T}(s) I_{i n}$. The current follower senses the current driven by the transimpedance amplifier and mirrors it to the negative output terminal.

According to the Rosenstark formulation [14], the exact closed-loop current gain, $G_{F}$, is related to the return ratio, $T$, the asymptotic gain, $G_{\infty}$, and the direct transmission gain, $G_{o}$ :

$$
G_{F}=G_{\infty} \frac{T}{1+T}+G_{o} \frac{1}{1+T}
$$

All these quantities must be calculated with respect to one controlled source within the feedback amplifier (in this case the current controlled voltage source). The asymptotic gain, $G_{\infty}$, is given by

$$
G_{\infty}=\left.\frac{i_{\text {out }}^{+}}{i_{\text {in }}}\right|_{Z_{T} \rightarrow \infty}=1+\frac{R_{2}}{R_{1}}
$$

Copyright (c) 2014 IEEE. Personal use of this material is permitted. However, permission to use this material for any other purposes must be obtained from the IEEE by sending an email to pubs-permissions@ieee.org 
where $R_{1}$ and $R_{2}$ are the feedback network resistors.

The return ratio $T$ results to be

$$
\begin{gathered}
T(s)=\frac{Z_{T}(s) R_{1}}{\left(R_{2}+r_{i}\right)\left(R_{1}+r_{o}^{+}\right)+R_{1} r_{0}^{+}}= \\
=\frac{Z_{T}(s)}{r_{i}+r_{o}^{+} G_{\infty}+R_{2}+\frac{r_{i} r_{o}^{+}}{R_{2}}\left(G_{\infty}-1\right)}
\end{gathered}
$$

The forward gain $G_{o}$ is lower than 1 and, being divided by $1+T$ in (1), is negligible.

If $R_{1}, R_{2}>>r_{i}, r_{0}^{+}, T(s)$ can be approximated as

$$
T(s) \cong \frac{Z_{T}(s)}{R_{2}}
$$

and the closed loop bandwidth $\omega_{C L}$ expressed as a function of the open loop bandwidth, $\omega_{O L}$, is

$$
\omega_{C L} \cong(1+T(0)) \omega_{O L} \cong T(0) \omega_{O L}=\frac{Z_{T}(0) \omega_{O L}}{R_{2}}
$$

Comparing (2) and (5), we see that while the asymptotic gain depends on both feedback network elements $\left(R_{1}\right.$ and $\left.R_{2}\right)$, the closed loop bandwidth only depends on $R_{2}$. Therefore, this system behaves like a CFVOA with constant closed-loop bandwidth provided that different gains are set by changing $R_{1}$ alone.

Finally, it is worth mentioning that another advantage of VFCOAs is the possibility of using non-linear resistors in the feedback loop without worsening the linearity of the system [13]. This is possible because the virtual ground at the input enforces equal voltage drops across both resistors, allowing cancellation of nonlinear terms.

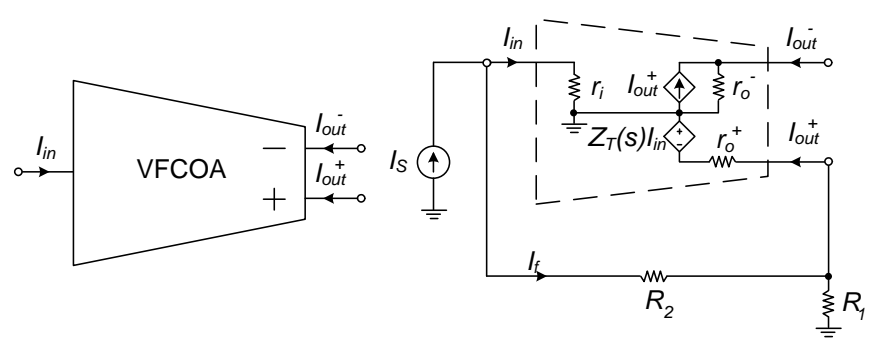

(a)

(b)

Fig. 1. The VFCOA: (a) symbol, (b) equivalent circuit with typical feedback configuration for accurate current gain.

\section{B. Feedback resistors design}

If the feedback resistors $R_{1}$ and $R_{2}$ are simultaneously changed in such a way that their ratio $R_{2} / R_{1}$ remains constant, the asymptotic gain (i.e., the ideal gain) in (2) remains constant, but return ratio in (3) goes through a maximum. This maximum occurs for two optimum values of $R_{1}$ and $R_{2}$ so that

$$
R_{1, \text { opt }} R_{2, o p t}=r_{i} r_{0}^{+}
$$

thus, evaluating $R_{2}$ from (2) and substituting into (6) we get

$$
R_{1, \text { opt }}=\sqrt{\frac{r_{i} r_{o}^{+}}{G_{\infty}-1}} \text { and } R_{2, \text { opt }}=\sqrt{r_{i} r_{o}^{+}\left(G_{\infty}-1\right)}
$$

This means that for any $G_{\infty}$ there is a different optimum setting of $R_{1}$ (and $R_{2}$ ). It is hence apparent that there is no possibility to set a constant $R_{2}$ for different $G_{\infty}$ while maximizing the return ratio. Moreover, the resulting value of $R_{1, \text { opt }}$ is not practical because it is in general too small (for instance, if $r_{\mathrm{i}}=r_{\mathrm{O}}+=50 \Omega$ and $G_{\infty}=11$, then $R_{1, \mathrm{opt}}$ is around 16 $\Omega^{1}$.

The use of non optimum resistances determines a return ratio reduction with respect to the maximum return ratio, $T_{\text {MAX }}(s)$,

$$
T_{M A X}(s)=\frac{Z_{T}(s)}{r_{i}+r_{o}^{+} G_{\infty}+2 \sqrt{r_{i} r_{o}^{+}\left(G_{\infty}-1\right)}}
$$

given by

$$
\frac{T(s)}{T_{M A X}(s)}=\frac{1+\frac{r_{o}^{+}}{r_{i}} G_{\infty}+2 \sqrt{\frac{r_{o}^{+}}{r_{i}}\left(G_{\infty}-1\right)}}{1+\frac{r_{o}^{+}}{r_{i}} G_{\infty}+\frac{R_{2}}{r_{i}}+\frac{r_{o}^{+}}{R_{2}}\left(G_{\infty}-1\right)}
$$

Relationship (9) is plotted in Fig. 2, where the reduction is expressed in $\mathrm{dB}$ versus $R_{2} / r_{\mathrm{i}}$, for four different asymptotic gains $\left(r_{\mathrm{i}}=r_{\mathrm{o}}{ }^{+}\right.$is assumed for simplicity).

As expected, the return ratio reduction, from its minimum value, increases with $R_{2} / r_{\mathrm{i}}$ and is greater for lower closed-loop gains. A tradeoff must hence be met to avoid excessive loop gain reduction while obtaining a nearly constant closed loop bandwidth. From Fig. 2, it is seen that an acceptable maximum loop gain reduction less than $15 \mathrm{~dB}$ is obtained by choosing $R_{2} / r_{\mathrm{i}}=20$ (for instance, if $r_{\mathrm{i}}=50 \Omega, R_{2}=1 \mathrm{k} \Omega$ can be set).

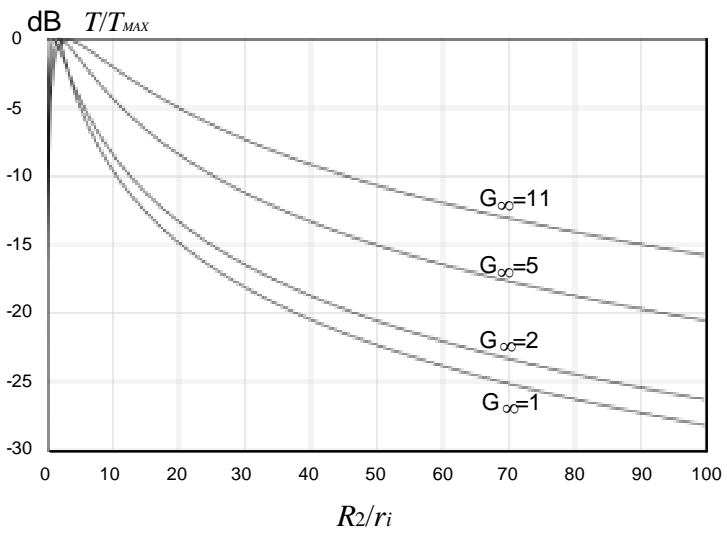

Fig. 2. $T / T_{M A X}$ versus $R_{2} / r_{i}$ for different values of $G_{\infty}$

\section{The Designed CIRCUIT}

\section{A. Block diagram}

Fig. 3 shows the block diagram of a VFCOA designed using the most versatile current mode circuit: the second generation current conveyor (CCII \pm ) [15]-[17], a three port network whose mathematical relationship between the $\mathrm{X}, \mathrm{Y}$, and $\mathrm{Z}$ terminals is represented by the following equation.

$$
\left(\begin{array}{c}
I_{Y} \\
V_{X} \\
I_{Z}
\end{array}\right)=\left(\begin{array}{ccc}
0 & 0 & 0 \\
1 & 0 & 0 \\
0 & \pm 1 & 0
\end{array}\right)\left(\begin{array}{c}
V_{Y} \\
I_{X} \\
V_{Z}
\end{array}\right)
$$

where $I_{Z}=+I_{X}$ and $I_{Z}=-I_{X}$ represent the CCII+ and

\footnotetext{
1 A low $R_{1}$ value causes both poor matching with $R_{2}$ and large output offset current, $V_{o s} / R_{1}$, where $V_{o s}$ is the input offset voltage.
} 
CCII-, respectively (note that positive currents are considered the ones "entering" into the node).

The transimpedance amplifier is implemented by $\mathrm{CCII}_{1}+$ and resistor $R_{T}$. Terminal $\mathrm{Y}_{1}$ is connected to a proper DC voltage for biasing purposes (ground if a dual supply voltage is used), which is replicated at the virtual ground terminal $X_{1}$. The current entering terminal $X_{1}$ is mirrored to terminal $Z_{1}$. As $\mathrm{Z}_{1}$ is connected to the compensation capacitor $C_{c}$ and node $\mathrm{Y}_{2}$ has very high impedance (ideally infinite, usually that of a MOS gate terminal), the $Z_{1}$ output current is driven to the parallel equivalent of the output impedance of $\mathrm{Z}_{1}, R_{T}$ and $C_{C}$. Considering dominant pole behavior in the $\mathrm{CCII}_{1}+$, the voltage at node $\mathrm{Z}_{1}$ is

$$
V_{Z 1}(s)=-I_{i n} \frac{R_{T}}{1+s R_{T} C_{C}}
$$

Subsequently, the voltage follower inside $\mathrm{CCII}_{2} \pm$ copies $V_{\mathrm{Z} 1}(s)$ from $\mathrm{Y}_{2}$ to $\mathrm{X}_{2}$. The cutoff frequency of this voltage follower sets the feedback-loop second pole, which should be much higher than the dominant pole in order to have enough phase margin and keep the loop stable. For this reason, $\mathrm{CCII}_{2} \pm$ 's voltage follower bandwidth becomes an important design parameter. The only way to achieve high current driving capability while maintaining low power consumption is using a class $A B$ topology [18], [19].

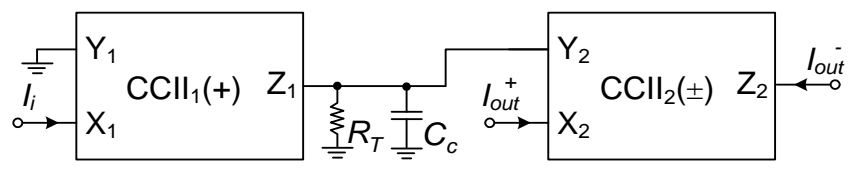

Fig. 3. Block diagram of the VFCOA [11].

\section{B. Implementation}

Fig. 4 shows the class $\mathrm{AB}$ CCII+ implementation. It was presented as a current mirror in [20], but it will be shown that it can also be used as a CCII+. The circuit combines very low input impedance at node $X$, very high output impedance at node $\mathrm{Z}$, ideally infinite input impedance at node $\mathrm{Y}$, low power consumption and high linearity and current capability. The structure is based on the typical wide-swing cascode NMOS current mirror, which was chosen since it increases both linearity and output resistance. Although there are output stages capable of achieving higher output resistance and linearity [8], [21], [22], they are less power efficient.

The class $\mathrm{AB}$ operation is achieved transforming the PMOS static bias current circuit $\mathrm{M}_{\mathrm{P} 1-2}$ into a quasi-floating gate (QFG) dynamic bias current mirror [20]. The DC voltage at the gates of $\mathrm{M}_{\mathrm{P} 1-3}$ is equal because there is no $\mathrm{DC}$ current going through capacitor $C_{b a t}$, therefore, the DC voltage drop across $R_{\text {large }}$ is zero. Thus in DC $C_{b a t}$ and $R_{\text {large }}$ have no effect, and $\mathrm{M}_{\mathrm{P} 1-2}$ act as conventional current sources of value $I_{B}$. This way the static currents are accurately set and can be made very low. Under dynamic operation, the voltage swing at $\mathrm{M}_{\mathrm{N} 1-2}$ 's gate is transferred to $\mathrm{M}_{\mathrm{P} 1-2}$ 's gate through the high pass filter formed by $C_{b a t}$ and $R_{\text {large }}$. Using the $R_{\text {large }}$ implementation shown in the inset of Fig. 4 (PMOS transistor in cutoff region) extremely high resistance values can be achieved, obtaining a cutoff frequency below $1 \mathrm{~Hz}$. Thus in practice $C_{b a t}$ acts as a floating battery in $\mathrm{AC}$, transferring any $\mathrm{AC}$ signal. This can lead to currents in $\mathrm{M}_{\mathrm{P} 2}$ much larger than $I_{B}$, achieving class $\mathrm{AB}$ operation. For more information about this technique the reader is referred to [20].

The error amplifier in the input loop, A, is used to create a virtual ground at the input $\mathrm{X}$ with $\mathrm{DC}$ input voltage accurately set by the DC voltage at node Y. Input resistance at node X and output resistance at node $\mathrm{Z}$ are given by

$$
\begin{gathered}
r_{\text {inX }}=g_{m C P 1} r_{d s P 1} r_{d s C P 1} \| \frac{1}{A g_{m N 1}} \cong \frac{1}{A g_{m N 1}} \\
r_{\text {outZ }}=g_{m C N 2} r_{d s N 2} r_{d s C N 2} \| g_{m C P 2} r_{d s P 2} r_{d s C P 2}
\end{gathered}
$$

With suitable dimensioning and biasing, values around $50 \Omega$ and $10 \mathrm{M} \Omega$ for $r_{\text {inX }}$ and $r_{\text {out }}$ respectively are easy to achieve. Fig. 4 also shows how Miller compensation is employed to stabilize the loop.

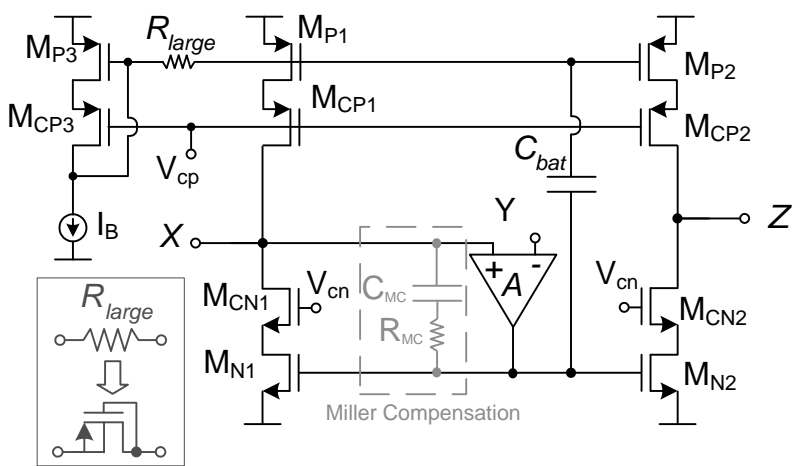

Fig. 4. The class AB CCII+ [20].

Fig. 5 shows the error amplifier used in $\mathrm{CCII}_{1}$. The wellknown differential pair with active load has been chosen due to its simplicity and low current requirements. It provides a gain $A$, equal to $g_{P 5}\left(r_{d P S} / / r_{d N N 3}\right)$. A similar solution is adopted for the implementation of $\mathrm{CCII}_{2}$.

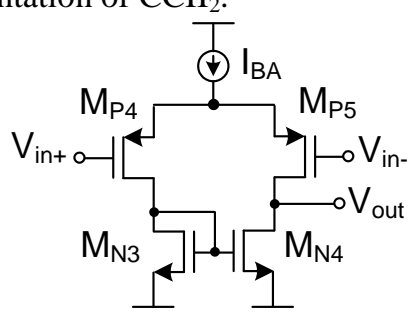

Fig. 5. Implementation of error amplifier in Fig. 4.

\section{The Feedback Network}

As mentioned above, it is possible to use non-linear elements in the feedback network without degrading the circuit linearity [13]. Fig. 6 shows the feedback network used in this work. Transistors $\mathrm{M}_{\mathrm{SW}}$ are used as switches, while transistors $\mathrm{M}_{\mathrm{PR} 1-2}$ are used as active resistors ${ }^{2}$. If $\mathrm{M}_{\mathrm{PR} 1-2}$ are matched and biased by $V_{R}$, their equivalent resistance $R\left(V_{R}\right)$ is equal. Therefore, $R_{2}=R\left(V_{R}\right)$ and $R_{1}=R\left(V_{R}\right) / n$, where $n$ (

\footnotetext{
${ }^{2}$ Due to the larger switching transistors, a slightly lower capacitance at node $\mathrm{X}_{2}$ (Fig. 3) is obtained by exchanging the position of $M_{\mathrm{PR} 1}$ with $\mathrm{M}_{\mathrm{Sw}}$.
} 
$n \subset 0: N)$ is the number of $\mathrm{M}_{\mathrm{PR} 1}$ active transistors. If we substitute these relationships into (2) and (5) the gain and closed loop bandwidth of the VFCOA are given by

$$
\begin{gathered}
G_{\infty} \cong 1+\frac{R_{2}}{R_{1}}=1+\frac{n R\left(V_{R}\right)}{R\left(V_{R}\right)}=1+n \\
\omega_{C L} \cong T(0) \omega_{O L}=\frac{Z_{T}(0) \omega_{O L}}{R\left(V_{R}\right)}
\end{gathered}
$$

From (14) and (15) we see that the closed-loop gain depends solely on the number of active transistor while the closed loop bandwidth depends on the tuning voltage $V_{R}$. Therefore the possibility of having constant, but tunable, closed-loop bandwidth is achieved.

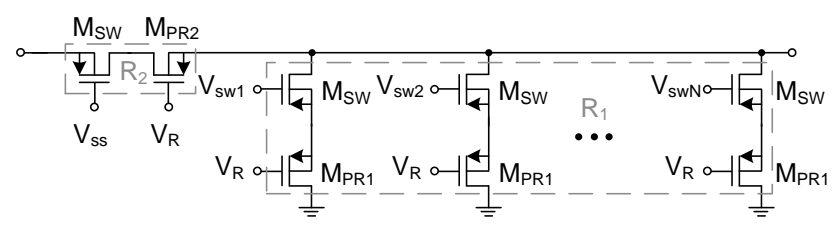

Fig. 6. Adopted transistorized feedback network.

\section{MEASUREMENT RESUltS}

The proposed VFCOA has been fabricated in a $0.5-\mu \mathrm{m}$ CMOS technology. $C_{b a t}, C_{C}$ and $C_{M C}$ were implemented as poly-poly capacitors with a nominal value of $1 \mathrm{pF}, 18 \mathrm{pF}$ and $1.5 \mathrm{pF}$ respectively. Resistors $R_{\text {large }}\left(\mathrm{M}_{\mathrm{PR}}\right)$ were implemented with minimum-size PMOS transistors $(1.5 \mu \mathrm{m} / 0.6 \mu \mathrm{m})$ and $R_{M C}$ has a nominal value of $2.5 \mathrm{k} \Omega$. The rest of the transistor's dimensions W/L (in $\mu \mathrm{m} / \mu \mathrm{m})$ were: 100/0.6 $\left(\mathrm{M}_{\mathrm{P} 1}, \mathrm{M}_{\mathrm{P} 2}, \mathrm{M}_{\mathrm{P} 3}\right.$, $\left.\mathrm{M}_{\mathrm{CN} 1}, \mathrm{M}_{\mathrm{CN} 2}\right)$ 200/0.6( $\left.\mathrm{M}_{\mathrm{CP} 1}, \mathrm{M}_{\mathrm{CP} 2}, \mathrm{M}_{\mathrm{CP} 3}\right) 60 / 1\left(\mathrm{M}_{\mathrm{N} 1}, \mathrm{M}_{\mathrm{N} 2}\right.$, $\left.\mathrm{M}_{\mathrm{N} 3}, \mathrm{M}_{\mathrm{N} 4}\right), 100 / 1\left(\mathrm{M}_{\mathrm{P} 4}, \mathrm{M}_{\mathrm{P} 5}\right), 50 / 0.6\left(\mathrm{M}_{\mathrm{SW}}\right)$ and $13.5 / 1\left(\mathrm{M}_{\mathrm{PR} 1}\right.$, $\mathrm{M}_{\mathrm{PR} 2}$ ).

Bias currents $I_{B}$ and $I_{B A}$ have been implemented as wide swing cascode current sources with a nominal value of $10 \mu \mathrm{A}$ and $5 \mu \mathrm{A}$ respectively. The supply voltage was $3.3 \mathrm{~V}$ achieving a total static power consumption of $280.5 \mu \mathrm{W}$. The total silicon area occupied by the whole circuit was $0.127 \mathrm{~mm}^{2}$, where the VFCOA and feedback network areas were $296 \times 380 \mu \mathrm{m}^{2}$ and $285 \times 50 \mu \mathrm{m}^{2}$ respectively. In Fig. 7 the VFCOA die microphotograph is shown.

Preliminary simulations showed a loop gain of $76 \mathrm{~dB}$, gainbandwidth product of $5.6 \mathrm{MHz}$ with a phase margin of $60^{\circ}$. Input resistance was $53 \Omega$ and resistance $\mathrm{R}_{2}$ was set nominally to $3500 \Omega$.

Figure 8 shows the measured VFCOA's magnitude response for different gain configurations. As it can be seen, the amplification range goes from 0 up to $23.63 \mathrm{~dB}$ with the bandwidth ranging from $1.8 \mathrm{MHz}$ to $2.9 \mathrm{MHz}$ for minimum and maximum gain respectively.

Measurement results also show that the bandwidth can be tuned between 1 and $3 \mathrm{MHz}$ using $V_{R}$. If lower/higher bandwidth values are needed, they can be easily achieved at the design stage by proper $\mathrm{M}_{\mathrm{PR}}$ dimensioning ${ }^{3}$.

\footnotetext{
${ }^{3}$ Although tunable bandwidth is not commonly employed in amplifiers, it can be used for instance in some low-cost low-power transceivers where a
}

The harmonic distortion for a $300-\mathrm{kHz}$ input signal is shown for minimum and maximum gain in Figs. 9 and 10, respectively (being the amplifier loaded with $R_{L}=5.6 \mathrm{k} \Omega$ ). As it can be seen, as usual in single-ended circuits, HD2 dominates over HD3. Class $\mathrm{AB}$ operation and high linearity can be appreciated by the fact that output total harmonic distortion is less than $-40 \mathrm{~dB}$ for output current amplitudes up to $5 I_{B}$ for minimum gain and $23 I_{B}$ in maximum gain configuration. Fig. 11 shows the step response of the VFCOA for maximum and minimum gain. Finally, Table I reports a comparison of the circuit performance parameters with those of the other two existing fabricated designs reported. Note that due to the class $\mathrm{AB}$ operation, this proposal achieves similar settling performance with less power consumption. Table II shows additional measurement results.

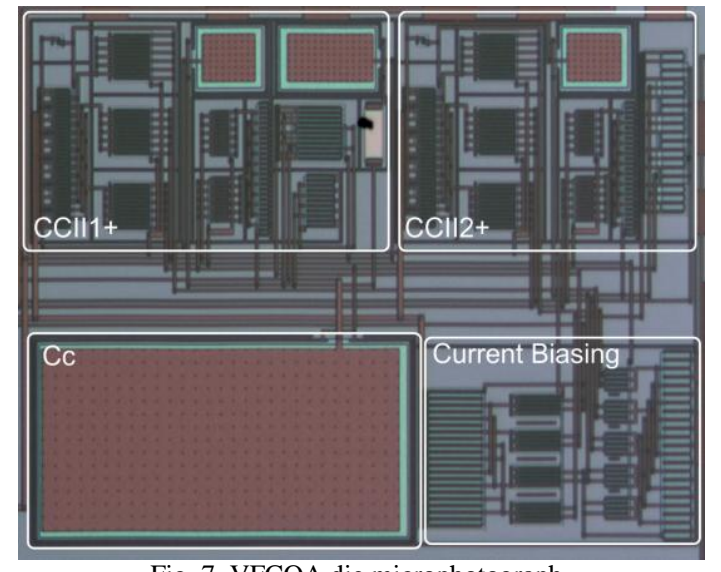

Fig. 7. VFCOA die microphotograph.

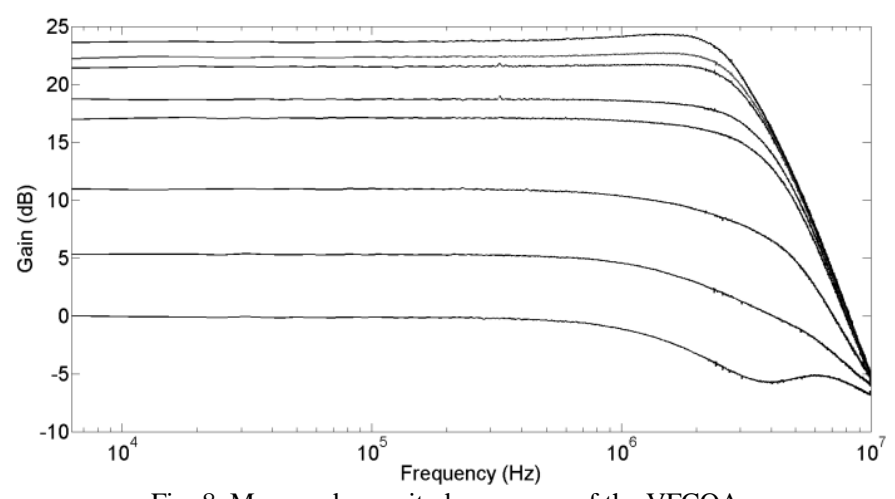

Fig. 8. Measured magnitude response of the VFCOA.

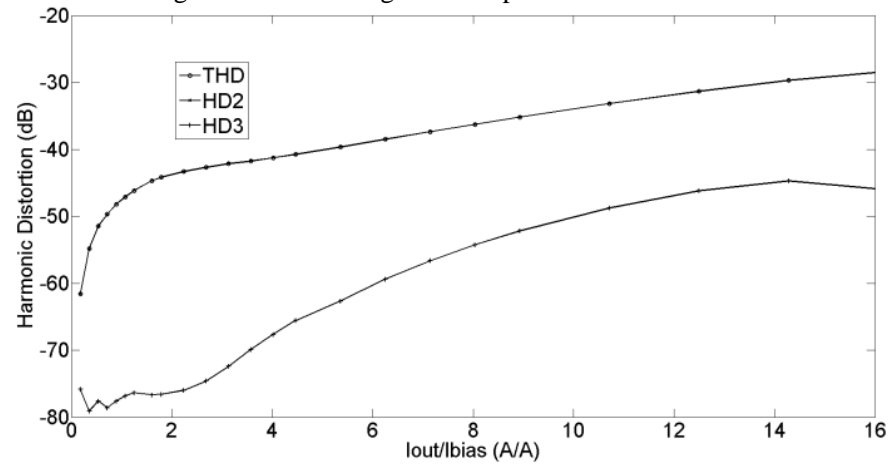

Fig. 9. VFCOA measured harmonic distortion for $0 \mathrm{~dB}$ gain @300kHz.

tunable bandwidth amplifier can help in the channel selectivity of the baseband section of the receiver, saving die area and power consumption. 


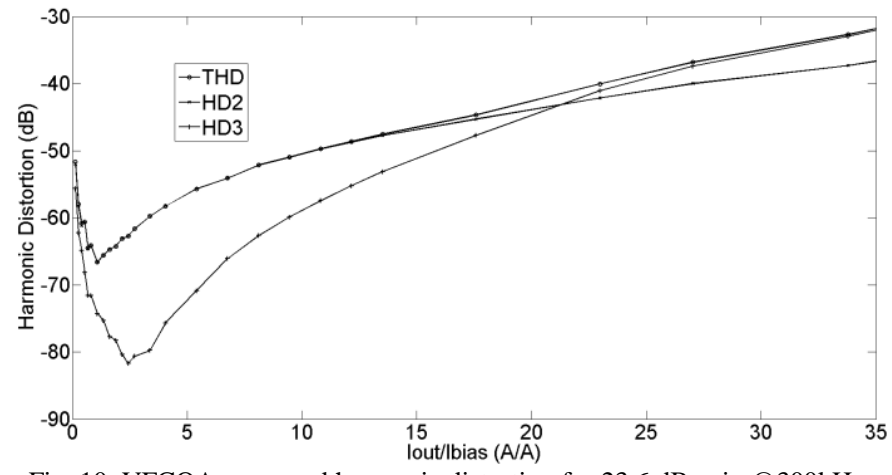

Fig. 10. VFCOA measured harmonic distortion for $23.6 \mathrm{~dB}$ gain @ $300 \mathrm{kHz}$.

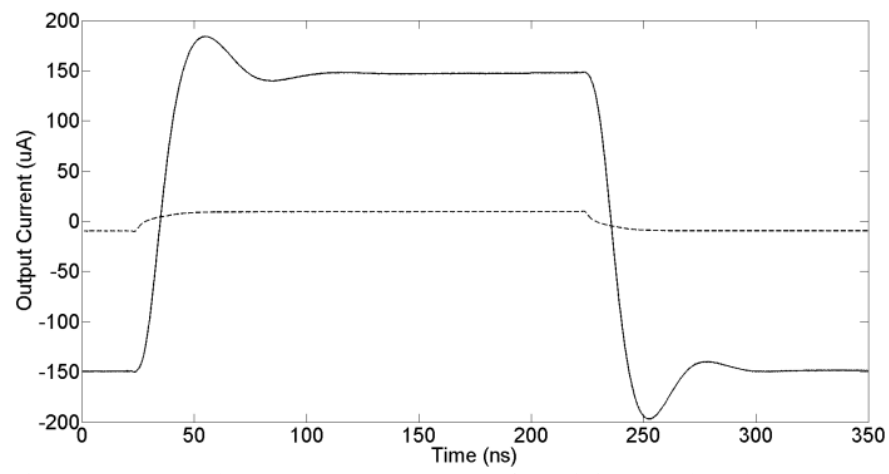

Fig. 11. Measured VCFOA step response for minimum (dotted curve) and maximum gain (continuous curve).

\section{CONCLUSION}

A class $\mathrm{AB}$ CMOS VFCOA that combines both variable gain and constant tunable bandwidth has been described in this brief, where the design strategy for the feedback resistors has also been discussed in detail. Measurement results confirm that the VFCOA is a versatile active block that can be used in high performance low power consumption current-mode circuit design. Measurement results show improved performance compared to similar circuits in literature, as apparently indicated by the figure of merit reported in the last row of Table I.

\section{REFERENCES}

[1] S. Franco, Design with Operational Amplifiers and Analog Integrated Circuits, 3rd ed, London, McGraw-Hill, 2003.

[2] W. Jung, Op Amp Applications Handbook, Burlington, Elsevier, 2005.

[3] A. S. Sedra and K. C. Smith, Microelectronic Circuits 6th ed., New York, Oxford University Press, 2010.

[4] R. Senani, D.R. Bhaskar, A.K. Singh and V.K. Singh, Current-feedback operational amplifiers and their applications, London, Springer, 2013.

[5] A. Soliman, "Applications of the current feedback operational amplifiers," Analog Integr. Circ. Sig. Proc., no. 11, pp. 265-302, 1996.

[6] G. Palumbo and S. Pennisi, "Current-feedback amplifiers versus voltage operational amplifiers", IEEE Trans. Circ. Syst. I, vol. 48, no. 5, pp. 617-623, 2001.

[7] S. Pennisi, G. Scotti and A. Trifiletti, "Avoiding the gain-bandwidth trade off in feedback amplifiers", IEEE Trans. Circ. Syst. I, vol. 58, no. 9, pp. 2108-2113, 2011.

[8] G. Palmisano, G. Palumbo and S. Pennisi, "Solutions for CMOS current amplifiers with high-drive output stages", IEEE Trans. Circ. Syst. II, vol. 47 , no. 10, pp. $988-998,2000$

[9] S. Pennisi, "A Low-Voltage Design Approach for Class AB CurrentMode Circuits", IEEE Trans. Circ. Syst. II, Vol. 49, No. 4, pp. 273-279, 2002.

[10] E. Bruun, "Constant-bandwidth current mode operational amplifier", Electron. Lett., vol. 27, no. 18, pp. 1673-1674, 1991.
[11] T. Kaulberg, "CMOS current-mode operational amplifier", IEEE J. SolidState Circ., vol. 28, no. 7, pp. 849-852, 1993.

[12] G. Palmisano, G. Palumbo and S. Pennisi, "High-Drive CMOS Current Amplifier", IEEE J. Solid-State Circ., Vol. 33, No. 2, pp. 228-236, 1998.

[13] L. Magram and A. Arbel, "Current-mode feedback amplifier employing a transistorized feedback network", in Proc. IEEE ISCAS, Vol. 5, pp. 607-610, 1994.

[14] S. Rosenstark, "A Simplified Method of Feedback Amplifier Analysis," IEEE Trans. Educat., Vol. E-17, No. 4, pp. 192-198, 1974.

[15] K.C. Smith and A. Sedra, "The current conveyor - a new circuit building block”, IEEE Proc. Vol. 56, No. 8, pp. 1368-1369, 1968.

[16] A. Sedra and K.C. Smith, "A second generation current conveyor and its applications", IEEE Trans., Vol. CT-17, No. 1, pp. 132-134, 1970.

[17] G. Palmisano, G. Palumbo and S. Pennisi, "Design Strategies for Class A CMOS CCIIs", Analog Integr. Circ. Sig. Proc., Vol. 19, No. 1, pp. 75-85, 1999.

[18] G. Palmisano and S. Pennisi, "Dynamic Biasing for True Low-Voltage CMOS CLASS AB Current-Mode Circuits", IEEE Trans. Circ. Syst. II, Vol. 47, No. 12, pp. 1569-1575, 2000.

[19] R. Mita, G. Palumbo and S. Pennisi, "1.5-V CCII+ with high currentdriving capability", IEEE Trans. Circ. Syst. II, Vol. 50, No. 4, pp. 187190, Apr. 2003.

[20] A.J. Lopez-Martin, J. Ramirez-Angulo, R.G. Carvajal and J.M Algueta, "Compact class AB CMOS current mirror," Electron. Lett., Vol.44, No.23, pp.1335-1336, 2008.

[21] F. Esparza-Alfaro, A.J. Lopez-Martin, J. Ramirez-Angulo and R.G. Carvajal, "High-performance micropower class AB current mirror," Electron. Lett. Vol.48, No.14, pp. 823-824, 2012.

[22] W. Aloisi, G. Giustolisi, and G. Palumbo, "Design and Comparison of Very Low-Voltage CMOS Output Stages," IEEE Trans. Circ. Syst. I, Vol.52, No.8, pp.1545-1556, 2005.

TABLE I

PERFORMANCE COMPARISON

\begin{tabular}{l|l|l|l}
\hline \hline Parameter & This work & {$[\mathbf{1 2}]$} & {$[\mathbf{1 1}]$} \\
\hline CMOS Technology $(\mu \mathrm{m})$ & 0.5 & 1.2 & 2.4 \\
\hline Die Area $\left(\mathrm{mm}^{2}\right)$ & 0.127 & 0.26 & NA \\
\hline Power Supply $(\mathrm{V})$ & 3.3 & 5 & 5 \\
\hline DC Power Consumption $(\mu \mathrm{W})$ & 280.5 & 4000 & $>1500$ \\
\hline Open-Loop Gain $(\mathrm{dB})$ & $76^{*}$ & 100 & 72 \\
\hline GBW $(\mathrm{MHz})$ & $5.6^{*}$ & 10 & 3 \\
\hline Phase Margin $(\mathrm{deg})$ & $60^{*}$ & $>60$ & 60 \\
\hline Output Load & $5.6 \mathrm{k} \Omega$ & $100 \Omega$ & $\mathrm{NA}$ \\
\hline$I_{O, M A X}(\mu \mathrm{A})$ & \pm 500 & \pm 700 & \pm 700 \\
\hline$I_{O, M A X} / I_{\text {Standby }}$ & 58.8 & 8.75 & $<2.3$ \\
\hline$T_{\text {Settl }(0.1 \%)}$ unity gain $(\mathrm{ns})$ & 47 & 165 & 35 \\
\hline$S R$, unity gain $(\mu \mathrm{A} / \mathrm{ns})$ & 3.3 & 200 & NA \\
\hline Input noise voltage $(\mathrm{nV} / \sqrt{\mathrm{Hz}})$ & 0.54 & 7.5 & NA \\
\hline Output noise current $(\mathrm{pA} / \sqrt{\mathrm{Hz})}$ & 5.7 & 20 & NA \\
& $(1 \mathrm{k} \Omega$ load $)$ & $(100 \Omega$ load $)$ & \\
\hline$T_{\text {Settl }(0.1 \%)} I_{O, M A X} / I_{\text {Standby }}(\mathrm{ns})$ & 2764 & 1443 & $<81$ \\
\hline \hline
\end{tabular}

TABLE II

Summary of AdDitional MEASUREd PERFormance

\begin{tabular}{l|l}
\hline \hline Parameter & Value \\
\hline BW Range $(\mathrm{MHz})$ & $1-3$ \\
\hline Gain Range $(\mathrm{dB})$ & $0-23.6$ \\
\hline $0.1 \%$ Settling time, max gain $(\mathrm{ns})$ & 138.4 \\
\hline Slew rate, max gain $(\mu \mathrm{A} / \mathrm{ns})$ & 28.4 \\
\hline$\Delta \mathrm{I}_{\text {out }} / \Delta \mathrm{V}_{\mathrm{DD}}$, unity gain, @ 100kHz $(\mu \mathrm{A} / \mathrm{V})$ & 24.6 \\
\hline$\Delta \mathrm{I}_{\text {out }} / \Delta \mathrm{V}_{\mathrm{Ss}}$, unity gain, @ 100kHz $(\mu \mathrm{A} / \mathrm{V})$ & 27.3 \\
\hline $\mathrm{IIP} 3$, unity gain $(\mathrm{dBm})$ & 29.3 \\
\hline $\mathrm{P} 1 \mathrm{~dB}$, unity gain $(\mathrm{dBm})$ & 10 \\
\hline $\mathrm{IIP} 3$, max gain $(\mathrm{dBm})$ & 12.6 \\
\hline $\mathrm{P} 1 \mathrm{~dB}$, max gain $(\mathrm{dBm})$ & -6.5 \\
\hline $\mathrm{DR}, \mathrm{THD} @ 300 \mathrm{kHz} 1 \%, \mathrm{~N}_{\mathrm{BW}} 2.9 \mathrm{MHz}$, max gain $(\mathrm{dB})$ & 87.5 \\
\hline $\mathrm{DR}, \mathrm{THD} @ 300 \mathrm{kHz} 1 \%, \mathrm{~N}_{\mathrm{BW}} 1.7 \mathrm{MHz}$, min gain $(\mathrm{dB})$ & 100.1 \\
\hline \hline
\end{tabular}

